\title{
Surgical volume and outcomes of off-pump coronary artery bypass graft surgery: Does it matter?
}

\author{
Suma H. Konety, MS, MD, ${ }^{\text {a }}$ Gary E. Rosenthal, MD, ${ }^{\text {b,c }}$ and Mary S. Vaughan-Sarrazin, PhD ${ }^{\mathrm{b}, \mathrm{c}}$
}

Objectives: Coronary artery bypass grafting performed off-pump has emerged in recent years as a less morbid alternative to on-pump bypass grafting. However, the impact of hospital volume on the outcomes of off-pump relative to on-pump bypass grafting has not been evaluated.

Methods: We conducted a retrospective study of patients undergoing off-pump $(\mathrm{n}=26,011)$ and on-pump $(\mathrm{n}=$ 99,344) coronary artery bypass grafting during 2000 through 2004 in 124 California hospitals, using the California Patient Discharge Database. Generalized linear mixed models were used to compare in-hospital mortality and postoperative complications in patients undergoing on-pump versus off-pump bypass grafting, accounting sequentially for differences in patient characteristics and hospital-level effects. The relative mortality and complication rates for patients undergoing on-pump versus off-pump coronary bypass were evaluated across hospital volume quartiles.

Results: Mean length of stay was lower for patients who underwent off-pump compared with on-pump bypass grafting ( 8.7 vs 9.6 days; $P<.001)$, as were unadjusted mortality and complication rates $(2.2 \%$ vs $3.3 \% ; 10.1 \%$ vs $11.6 \%$, respectively; $P<.001$ ). For hospitals in the highest percent off-pump bypass quartile, adjusted mortality and complication rates for patients having off-pump bypass were significantly lower than for the on-pump group (odds ratio $[\mathrm{OR}]=0.50 ; 95 \%$ confidence intervals $[\mathrm{CI}], 0.41-0.61 ; \mathrm{OR}=0.73 ; 95 \% \mathrm{CI}, 0.66-0.81$, respectively; $P<.001$ ); by contrast, for hospitals in the lowest percent off-pump bypass quartile, mortality and complications were similar in off-pump and on-pump groups $(\mathrm{OR}=1.10 ; 95 \% \mathrm{CI}, 0.75-1.63$; $\mathrm{OR}=0.92 ; 95 \% \mathrm{CI}$, $0.72-1.16$, respectively; $P>.05$ ).

Conclusions: Outcomes were significantly better for off-pump compared with on-pump coronary artery bypass grafting. Although the benefit of off-pump bypass grafting increased as the relative use of the procedure at a hospital increased, off-pump bypass grafting can be safely implemented across numerous hospitals.

\footnotetext{
From the Division of Cardiovascular Diseases, Department of Internal Medicine, University of California San Francisco, San Francisco, Calif, a the Division of General Internal Medicine, Department of Internal Medicine, University of Iowa Carver College of Medicine, Iowa City, Iowa, ${ }^{b}$ and the Center for Research in the Implementation of Innovative Strategies in Practice (CRIISP), Iowa City VA Medical Center, Iowa City, Iowa.

For data acquisition, management, and analysis, this research was supported, in part, by an award (HFP 04-149) from the Health Services Research and Development Service, Veterans Health Administration, Department of Veterans Affairs. Dr Rosenthal is a Senior Quality Scholar, Office of Academic Affiliation, Veterans Health Administration. Dr Konety was supported by a Cardiovascular Interdisciplinary Fellowship (HL 07121) from the University of Iowa Hospital and Clinics, Division of Cardiovascular Diseases. Dr Konety had full access to all of the data in the study and takes responsibility for the integrity of the data and the accuracy of the data analysis.

The views expressed in this article are those of the authors and do not necessarily represent the views of the Department of Veterans Affairs.

Drs Rosenthal and Vaughan-Sarrazin are supported by a grant (HFP 04-149) from the Health Services Research and Development Service, Veterans Health Administration, Department of Veterans Affairs. Dr Konety was supported by a Cardiovascular Interdisciplinary Fellowship (HL 07121) from the University of Iowa Hospitals and Clinics, Division of Cardiovascular Diseases.

Received for publication April 5, 2007; revisions received Dec 4, 2008; accepted for publication Dec 27, 2008.

Address for reprints: Suma H. Konety, MS, MD, Division of Cardiovascular Diseases, Department of Internal Medicine, UCSF Medical Center, 505 Parnassus Ave, Room M322, Box 0214, San Francisco, CA $94143-0214$ (E-mail: konetys@medicine. ucsf.edu).

J Thorac Cardiovasc Surg 2009;137:1116-23

$0022-5223 / \$ 36.00$

Copyright (c) 2009 by The American Association for Thoracic Surgery doi:10.1016/j.jtcvs.2008.12.038
}

$\mathcal{B}$ Supplemental material is available online.

Coronary artery bypass graft grafting (CABG) without the use of cardiopulmonary bypass, or off-pump CABG, is considered to be a less morbid alternative to CABG with the use of cardiopulmonary bypass, or on-pump CABG. Roughly $20 \%$ to $25 \%$ of CABG procedures in the United States are performed off-pump (http://www.sts.org). However, definitive data establishing the superiority of off-pump CABG over on-pump CABG are lacking. ${ }^{1,2}$

There have been more favorable data with regard to operative mortality and morbidity for off-pump CABG compared with on-pump CABG from prior retrospective studies $^{3-5}$ than from randomized controlled trials. ${ }^{6,7}$ Previous trials have generally enrolled low-risk patients and have been conducted predominantly in one or only a few centers, ${ }^{8-10}$ and the generalizability of these results is unclear. However, questions about possible selection bias in the referral of cases more easily amenable to off-pump CABG remain. Conflicting information regarding efficacy of off-pump CABG from prior studies has led to inconsistent 


\section{Abbreviations and Acronyms \\ $\mathrm{CABG}=$ coronary artery bypass grafting \\ $\mathrm{CI}=$ confidence intervals \\ $\mathrm{OR} \quad=$ odds ratio}

adoption of off-pump CABG as an alternative to on-pump CABG in the United States.

Given the technical difficulty of performing off-pump $\mathrm{CABG}$, it is likely that a strong relationship exists between off-pump CABG volume and outcomes, and this has not been investigated thoroughly. A number of investigations of the relationship between hospital volume and outcomes for overall CABG have been conducted. ${ }^{11-13}$ Historically, one explanation for the finding that higher volumes are associated with better outcomes is the "learning curve" (ie, " "practice makes perfect"), such that volume reflects attainment of a certain level of skill. ${ }^{12}$

We conducted a retrospective cohort study of patients undergoing CABG during 2000 through 2004 in the state of California to compare risk-adjusted mortality and postoperative complications among patients who underwent offpump and on-pump CABG. We hypothesized that the relative difference in outcomes between patients who underwent off-pump and on-pump CABG depends on the relative volume of each type of operation performed in those hospitals. We further hypothesized that outcomes of off-pump CABG may be better, relative to on-pump CABG, in hospitals that perform large numbers of off-pump CABG operations.

\section{METHODS}

\section{Patients}

The study used the California Patient Discharge Database from January 1, 2000, through December 31, 2004, available from the California Office of Statewide Health Planning and Development. Each record in the data set represents discharge abstracts from all nonfederal hospitals in California and is compiled annually. Data elements include the following: demographic information (eg, sex, race, ethnicity, age), patients' residence ZIP code; the diagnosis-related group; admission source (eg, transfer from another hospital, emergency room); length of stay, year and quarter of admission; discharge disposition; expected payer category; and a unique hospital identifier. Each record also provides a principal and up to 24 secondary diagnosis codes, with separate indicators for conditions present at admission, and a principal and 20 secondary procedure codes with separate variables measuring the number of days from admission to each procedure. All procedures and diagnoses are coded using the International Classification of Disease, 9th Revision, Clinical Modification (ICD-9-CM).

All patients undergoing CABG surgery during the study period were identified ( $\mathrm{n}=141,425$ on the basis of specific ICD-9-CM procedure codes (36.10-36.19). Patients were excluded if the procedure was coded as occurring in non-acute care hospitals (eg, skilled nursing facilities) $(n=59)$ or if it occurred in a facility that performed fewer than 10 CABGs during the study period $(\mathrm{n}=31)$. Patients simultaneously undergoing valve replacement $(\mathrm{n}=15,980)$ were excluded. The final sample consisted of 125,355 patients undergoing isolated CABG operations in 124 California hospitals. The presence of ICD-9-CM procedural code for intracorporeal pump (39.61) or cardioplegia (39.63) was used to distinguish between patients who underwent on-pump CABG ( $\mathrm{n}=99,344$ [79\%]) or off-pump CABG $(n=26,011[21 \%])$.

Records in the California data set with unique combinations of a select set of demographic variables have one or more of these variables masked to ensure de-identification of the data and thereby protect patient confidentiality. Thus, age category, sex, or race was unavailable for some records $(\mathrm{n}=$ $45,725)$. Patients with missing age, race, or gender information were not excluded initially but instead were identified by indicators for missing values in risk adjustment models. A second set of analyses excluded these patients.

Study end points included in-hospital mortality and postoperative complications, which were defined using seven conditions. Two complications, postoperative myocardial infarction and stroke, were identified with ICD-9CM diagnosis codes; these conditions were considered complications if the "present on admission" indicator, which is unique to the California data set, was not flagged. Five additional complications were identified using Patient Safety Indicators developed by the Agency for Healthcare Quality and Research (algorithms available at http://www.qualtiyindicators.ahrq.gov/ psidownload.htm), which are designed for use with administrative data and which are increasingly being used in research. ${ }^{14-16}$ The five complications included accidental puncture or laceration, postoperative hemorrhage or hematoma, respiratory failure, pulmonary embolism or deep vein thrombosis, and sepsis.

Hospital surgical volume for off-pump and total CABG were determined by summarizing the patient-level data by hospital identifier. Volume categories were defined in three ways. First, patients were grouped into quartiles according to the ratio of mean annual off-pump CABG volume to mean annual total $\mathrm{CABG}$ volume (ie, the percent of all $\mathrm{CABG}$ operations performed off-pump at the hospital where the operation occurred), resulting in the following categories: $6.4 \%$ or less, $6.5 \%$ to $11.1 \%, 11.2 \%$ to $22.8 \%$, and $23.7 \%$ or more. Second, quartiles were defined by the mean annual offpump CABG volume at the hospital where the operation occurred $(\leq 19$, $20-37,38-83$, and $\geq 85$ ). Finally, quartiles were created on the basis of the mean annual total CABG volume during the study period $(\leq 181$, 184-306, 307-509, and $\geq 517$ ).

\section{Risk Adjustment}

Bivariate associations between in-hospital mortality or postoperative complications and potential patient risk factors were determined by the Wilcoxon test or the $\chi^{2}$ statistic. Candidate variables included demographic factors, admission source, surgical priority, payer status, and comorbid conditions defined by ICD-9-CM codes with the criteria of Elixhauser and associates. ${ }^{17}$ The "present on admission" 'indicator was used to identify conditions present on admission and exclude conditions that developed during hospitalization. Additional risk factors included cardiogenic shock on admission, primary diagnosis of acute myocardial infarction, CABG performed on the same day as cardiac catheterization, CABG performed on the same day as admission, percutaneous coronary intervention before CABG (during the current admission), prior $\mathrm{CABG}$, prior percutaneous coronary intervention, and multivessel surgery. Variables associated $(P<.05)$ with a given end point in bivariate analyses were entered into a stepwise logistic regression. A propensity score was also calculated from logistic regression models based on patient characteristics to predict the likelihood of undergoing off-pump CABG versus on-pump CABG, and was used as an additional variable in the mortality and postoperative complications risk-adjustment models to further control for unmeasured patient characteristics. ${ }^{18,19}$

In the logistic regression models, age was expressed as four indicator variables (50-64 years, 65-74 years, $\geq 75$ years, and age unknown), with a referent category of less than 50 years. Race was expressed as white, African American, other, and unknown. Year of CABG was expressed using indicator variables for 2001, 2002, 2003, or 2004, with the period 2000 as the referent category. Admission type was expressed with an indicator variable for unscheduled admissions (relative to admissions that were scheduled or unknown type). Admission source was expressed as indicator variables for patients transferred to the hospital from another acute care facility and patients 
admitted through the emergency department, with a referent category that included primarily patients referred by a physician. Payer status was expressed as indicator variables for Medicare, Medicaid, Private Pay, and Managed Care with a referent category that included patients with no insurance. The discrimination of the logit models was determined with the c-statistic. ${ }^{20}$ Risk-adjusted models for mortality (c-statistic $=0.79$ ) and postoperative complications (c-statistic $=0.66)$ contained 38 and 34 variables, respectively, of which 26 were common to both models (E-Appendix).

\section{Estimating Relative Odds of Death and Complication}

The odds of death for off-pump CABG relative to on-pump CABG were estimated by logistic regression models with random hospital effects to account for the hierarchical levels of data (ie, patients within hospitals). ${ }^{21}$ First, models adjusted for patient characteristics only. Subsequent models also incorporated hospital-level effects using random intercepts and random coefficients for the off-pump CABG indicator for each hospital. In the latter set of models, intercepts and coefficients for the off-pump CABG indicator are allowed to vary across hospitals, and the overall intercept and off-pump CABG coefficient are the mean of the hospital-level intercepts and offpump CABG coefficients. In each set of models, the exponent of the overall coefficient for the off-pump CABG provides the odds of death (or complication) for off-pump relative to on-pump CABG. In addition, the variance of the hospital-level off-pump CABG random coefficients was estimated. This estimate reflects the degree to which the outcome for off-pump relative to on-pump CABG varies across hospitals.

Additional models were developed to evaluate whether hospital volume explained the variability in relative outcomes across hospitals by including interactions between the off-pump CABG indicator and volume quartile indicators, with separate models generated for three different volume quartile categories (percent off-pump CABG, off-pump CABG, and total CABG). The exponents of the regression coefficients associated with the interaction terms provide the adjusted odds of death for patients undergoing off-pump CABG relative to on-pump CABG in hospitals in each volume quartile. In addition, the proportion of total variance of the hospital-level off-pump coefficient that was explained by the volume quartiles was calculated as the difference between the total variance of the hospital-level offpump coefficients and the unexplained variance in models that included the volume category interaction terms, divided by the total variance.

All reported $P$ values are 2-tailed. Statistical analysis was performed with the SAS software system for Windows version 9.2 (SAS Institute, Inc, Cary, NC) and HLM 6.02 (Scientific Software International, 2005).

\section{RESULTS \\ Patient Characteristics}

The use of off-pump CABG was slightly more common in women than men and in non-whites than whites (Table 1). Off-pump CABG was somewhat less common in patients with diabetes, hypertension, and congestive heart failure, but more common for patients with chronic renal failure. The median postoperative length of stay for patients undergoing off-pump CABG was shorter than for patients undergoing on-pump CABG ( 7 vs 8 days; $P<.001$ ), with interquartile ranges of 5 to 10 and 6 to 11 , respectively. The use of off-pump CABG also increased over time, from $15.3 \%$ in 2000 to $21.1 \%$ in $2004(P<.001)$.

\section{Unadjusted Outcomes}

Unadjusted mortality and postoperative complications were lower in off-pump CABG patients than in on-pump CABG patients $(2.2 \%$ vs $3.3 \%$ and $10.1 \%$ vs $11.6 \%$, re- spectively; $P<.001)$. Among the postoperative complications, rates of myocardial infarction, stroke, sepsis, and hemorrhage were lower in the off-pump CABG patients; however, rates of accidental puncture or laceration were somewhat higher (Table 2). Mortality rates and complication rates associated with off-pump CABG declined as the percent of off-pump procedures performed by hospitals increased (Table 3). A similar but somewhat less direct trend was seen for the total off-pump procedures.

\section{Adjusted Outcomes}

After adjustment for patient characteristics, the overall odds of mortality and postoperative complications were lower for patients undergoing off-pump CABG relative to on-pump CABG (odds ratio $[\mathrm{OR}]=0.65 ; 95 \%$ confidence intervals [CI], 0.59-0.72; OR $=0.86 ; 95 \%$ CI, 0.81-0.90, respectively; $P<.001$ ). Further accounting for hospital-level effects had very little additional effect on the relative odds of mortality but yielded a lower relative odds of complication for the off-pump CABG group (OR $=0.65 ; 95 \% \mathrm{CI}, 0.57-0.76$; $\mathrm{OR}=0.80 ; 95 \%$ CI, 0.74-0.86, respectively; $P<.001$ ).

In models that included interactions between the off-pump CABG and percent off-pump CABG volume quartiles, the relative odds of death varied substantially depending on the relative use of off-pump or on-pump CABG at a given hospital and according to the absolute hospital off-pump volume (Table 4). For hospitals in the lowest quartiles of percent off-pump CABG and off-pump CABG, adjusted mortality and complications in off-pump patients were similar to those for on-pump patients. However, mortality and complications decreased steadily as the relative use of off-pump CABG at a hospital increased. For example, for hospitals in the highest quartile of percent off-pump CABG, the odds of mortality and complications for off-pump CABG patients were $50 \%$ and $27 \%$ lower, respectively, than for on-pump CABG patients. These relationships were not observed in analyses that examined total CABG volume quartiles. In addition, the percent off-pump CABG quartiles explained $39 \%$ of the variability in the relative odds of death and $15 \%$ of the variability in the relative odds of complications associated with pump use across hospitals; by contrast, the off-pump CABG volume quartiles explained only $23 \%$ of the variability in the relative odds of death and $0 \%$ of the variability in the relative odds of complications. The total CABG volume quartiles did not explain any of the error variance associated with pump use across hospitals.

Separate analyses were then performed excluding all patients with missing demographic information, leaving a total sample size of 79,630 patients, and results were very similar to those reported above.

\section{DISCUSSION}

This is a large study that establishes a relationship of $\mathrm{CABG}$ volume on mortality and postoperative complications 
TABLE 1. Characteristics of patients who underwent on-pump or off-pump CABG in 2000 through 2004

\begin{tabular}{|c|c|c|c|}
\hline & $\begin{array}{c}\text { On-pump } \\
\text { CABG } \\
(n=99,344) \\
\end{array}$ & $\begin{array}{c}\text { Off-pump } \\
\text { CABG } \\
(\mathrm{n}=\mathbf{2 6 , 0 1 1}) \\
\end{array}$ & $\begin{array}{c}P \\
\text { value } \\
\end{array}$ \\
\hline \multicolumn{4}{|l|}{ Demographic } \\
\hline \multicolumn{4}{|l|}{ Age categories (y) } \\
\hline$<50$ & $5.4 \%$ & $5.2 \%$ & .31 \\
\hline $50-64$ & $32.8 \%$ & $31.2 \%$ & $<.001$ \\
\hline $65-74$ & $33.4 \%$ & $31.9 \%$ & $<.001$ \\
\hline$>75$ & $19.9 \%$ & $22.5 \%$ & $<.001$ \\
\hline Age unknown & $8.6 \%$ & $9.2 \%$ & .002 \\
\hline Female sex & $19.9 \%$ & $21.2 \%$ & $<.001$ \\
\hline Sex unknown & $28.3 \%$ & $27.8 \%$ & .07 \\
\hline Non-Hispanic white & $50.8 \%$ & $49.7 \%$ & .001 \\
\hline African American & $1.7 \%$ & $2.1 \%$ & $<.001$ \\
\hline All other non-white race & $4.7 \%$ & $6.1 \%$ & $<.001$ \\
\hline Race unknown & $36.5 \%$ & $36.6 \%$ & .77 \\
\hline \multicolumn{4}{|l|}{ Insurance type } \\
\hline Private & $36.3 \%$ & $38.1 \%$ & $<.001$ \\
\hline Medicare & $51.5 \%$ & $50.5 \%$ & .006 \\
\hline Medicaid/other government & $9.3 \%$ & $7.5 \%$ & $<.001$ \\
\hline \multicolumn{4}{|l|}{ Managed care } \\
\hline Yes & $53.9 \%$ & $49.6 \%$ & $<.001$ \\
\hline No & $46.1 \%$ & $50.4 \%$ & $<.001$ \\
\hline \multicolumn{4}{|l|}{ Admission source } \\
\hline Emergency department & $23.6 \%$ & $22.0 \%$ & $<.001$ \\
\hline Transferred from other facility & $21.4 \%$ & $18.9 \%$ & $<.001$ \\
\hline Other & $55.0 \%$ & $59.1 \%$ & $<.001$ \\
\hline \multicolumn{4}{|l|}{ Acuity factors } \\
\hline $\begin{array}{l}\text { Cardiac catheterization on day } \\
\text { of } \mathrm{CABG}\end{array}$ & $10.8 \%$ & $10.5 \%$ & .14 \\
\hline $\begin{array}{l}\text { PCI before CABG during index } \\
\text { admission }\end{array}$ & $2.8 \%$ & $3.1 \%$ & .03 \\
\hline Cardiogenic shock & $1.5 \%$ & $1.0 \%$ & $<.001$ \\
\hline Acute MI & $23.0 \%$ & $20.4 \%$ & $<.001$ \\
\hline Anterolateral wall MI & $4.6 \%$ & $4.2 \%$ & .004 \\
\hline Inferior wall MI & $5.1 \%$ & $3.9 \%$ & $<.001$ \\
\hline Subendocardial MI & $12.1 \%$ & $10.9 \%$ & $<.001$ \\
\hline Other MI & $1.2 \%$ & $1.6 \%$ & .14 \\
\hline Previous PCI & $12.1 \%$ & $13.0 \%$ & $<.001$ \\
\hline Previous CABG & $2.0 \%$ & $1.9 \%$ & .63 \\
\hline Multiple-vessel CABG & $89.3 \%$ & $71.6 \%$ & $<.001$ \\
\hline IABP before $\mathrm{CABG}$ & $3.4 \%$ & $3.1 \%$ & .04 \\
\hline $\begin{array}{l}\text { Emergency } \mathrm{CABG} \text { on day of } \\
\text { admission }\end{array}$ & $8.1 \%$ & $8.3 \%$ & .37 \\
\hline \multicolumn{4}{|l|}{ Coexisting conditions } \\
\hline Diabetes & $36.6 \%$ & $33.3 \%$ & $<.001$ \\
\hline Hypertension & $64.2 \%$ & $62.7 \%$ & $<.001$ \\
\hline $\begin{array}{l}\text { Chronic obstructive pulmonary } \\
\text { disease }\end{array}$ & $18.1 \%$ & $17.9 \%$ & .54 \\
\hline Congestive heart failure & $18.4 \%$ & $15.9 \%$ & $<.001$ \\
\hline Prior MI & $15.5 \%$ & $13.9 \%$ & $<.001$ \\
\hline Cerebrovascular disease & $7.4 \%$ & $7.4 \%$ & .83 \\
\hline Peripheral vascular disease & $11.2 \%$ & $11.7 \%$ & .05 \\
\hline Valve disease & $10.5 \%$ & $7.3 \%$ & $<.001$ \\
\hline Obesity & $12.4 \%$ & $11.2 \%$ & $<.001$ \\
\hline
\end{tabular}

TABLE 1. Continued

\begin{tabular}{lccc}
\hline & $\begin{array}{c}\text { On-pump } \\
\text { CABG } \\
(\mathbf{n}=\mathbf{9 9 , 3 4 4 )}\end{array}$ & $\begin{array}{c}\text { Off-pump } \\
\text { CABG } \\
(\mathbf{n}=\mathbf{2 6 , 0 1 1})\end{array}$ & $\begin{array}{c}\boldsymbol{P} \\
\text { value }\end{array}$ \\
\hline Liver disease & $0.8 \%$ & $0.9 \%$ & .06 \\
Renal failure & $4.4 \%$ & $4.8 \%$ & .01 \\
\hline
\end{tabular}

With the exception of age, income, and length of stay, all data are percentages. Plusminus values are means \pm standard deviation. $C A B G$, Coronary artery bypass graft; $P C I$, percutaneous coronary intervention; $M I$, myocardial infarction; $I A B P$, intra-aortic balloon pump.

in patients undergoing off-pump CABG compared with onpump CABG. Overall, mortality and postoperative complications were lower in patients who underwent off-pump CABG relative to on-pump CABG. Rates of death and complication were similar for on- and off-pump CABG in hospitals performing the fewest off-pump CABG procedures, but decreased for off-pump relative to on-pump CABG as the absolute number and proportion of off-pump procedures increased. Moreover, the percent of $\mathrm{CABG}$ procedures performed off-pump explained a substantial proportion of the variability in the relative mortality of on- and off-pump CABG across hospitals.

Birkmeyer and associates, ${ }^{11}$ using Medicare data, showed that the overall mortality after CABG was $40 \%$ higher for hospitals in the lowest volume quintile compared with hospitals in the highest quintile. Importantly, these relationships may not be due to differences in patient characteristics ${ }^{11,13}$ or hospital characteristics ${ }^{22,23}$ and could remain, even after accounting for physician volumes-indicating that much of the volume-outcome relationship is attributable to organizational factors and not merely physician technical skill. ${ }^{24,25} \mathrm{Al}-$ though recent studies have demonstrated that volume is a weak predictor of outcomes, ${ }^{26,27}$ our study shows that the proportion of $\mathrm{CABG}$ procedures performed off-pump may be more important than the actual volume of off-pump CABG operations performed at a hospital. This suggests that some hospitals may "specialize" in off-pump procedures

TABLE 2. Unadjusted outcomes of patients who underwent on-pump or off-pump CABG in 2000 through 2004

\begin{tabular}{lccc}
\hline & $\begin{array}{c}\text { On-pump } \\
\text { CABG } \\
(\mathbf{n}=\mathbf{9 9 , 3 4 4 )}\end{array}$ & $\begin{array}{c}\text { Off-pump } \\
\text { CABG }\end{array}$ & $\boldsymbol{P}$ \\
& $\mathbf{n}=\mathbf{2 6 , 0 1 1})$ & value \\
\hline In-hospital mortality & $3.3 \%$ & $2.2 \%$ & $<.001$ \\
Postoperative complications & $11.6 \%$ & $10.1 \%$ & $<.001$ \\
$\quad$ Deep vein thrombosis/pulmonary & $0.6 \%$ & $0.5 \%$ & .21 \\
$\quad$ embolism & & & \\
Hemorrhage/hematosis & $5.7 \%$ & $5.1 \%$ & $<.001$ \\
Postoperative sepsis & $1.4 \%$ & $1.2 \%$ & .002 \\
Accidental puncture or laceration & $0.8 \%$ & $1.1 \%$ & .003 \\
Postoperative renal failure & $2.4 \%$ & $2.3 \%$ & .11 \\
Postoperative myocardial infarction & $1.8 \%$ & $1.5 \%$ & .009 \\
Postoperative stroke & $1.1 \%$ & $0.7 \%$ & $<.001$ \\
\hline
\end{tabular}

$C A B G$, Coronary artery bypass grafting. 
TABLE 3. Association of in-hospital mortality, postoperative complications, and hospital volume in patients undergoing off-pump CABG compared with on-pump CABG

\begin{tabular}{|c|c|c|c|c|}
\hline & \multicolumn{4}{|c|}{ Percent of CABG procedures performed off-pump (quartiles) } \\
\hline & Low (1) & Medium (2) & High (3) & Very high (4) \\
\hline Range $(\%)$ & $\leq 6.4$ & $6.5-1.1$ & $11.2-22.8$ & $23.7-89.2$ \\
\hline Median (min-max) off-pump CABG & $10(2-37)$ & $28(4-112)$ & $58(4-158)$ & $>86(9-509)$ \\
\hline Median (min-max) total CABG & $326(37-1280)$ & $350(62-1163)$ & $320(24-1310)$ & $218(29-768)$ \\
\hline No. of hospitals & 25 & 29 & 30 & 40 \\
\hline No. of patients & 30,834 & 31,896 & 30,801 & 31,824 \\
\hline Observed mortality rate $(\% *)$ & 3.5 & 2.9 & 2.4 & 1.9 \\
\hline Unadjusted mortality odds ratio $(95 \% \mathrm{CI})$ & $1.26(0.90-1.75)$ & $0.85(0.68-1.05)$ & $0.80(0.67-0.97)$ & $0.41(0.36-0.47)$ \\
\hline Observed complication rate $(\% *)$ & 9.5 & 10.6 & 9.4 & 10.2 \\
\hline Unadjusted complications odds ratio $(95 \% \mathrm{CI})$ & $0.94(0.77-1.15)$ & $0.84(0.75-0.95)$ & $0.86(0.78-0.95)$ & $0.69(0.64-0.74)$ \\
\hline
\end{tabular}

*Cochran-Armitage Trend Test between mortality and volume quartile: $P<.001$ (in-hospital mortality); $P=.30$ (complications).

Total CABG procedures performed off-pump (quartiles)

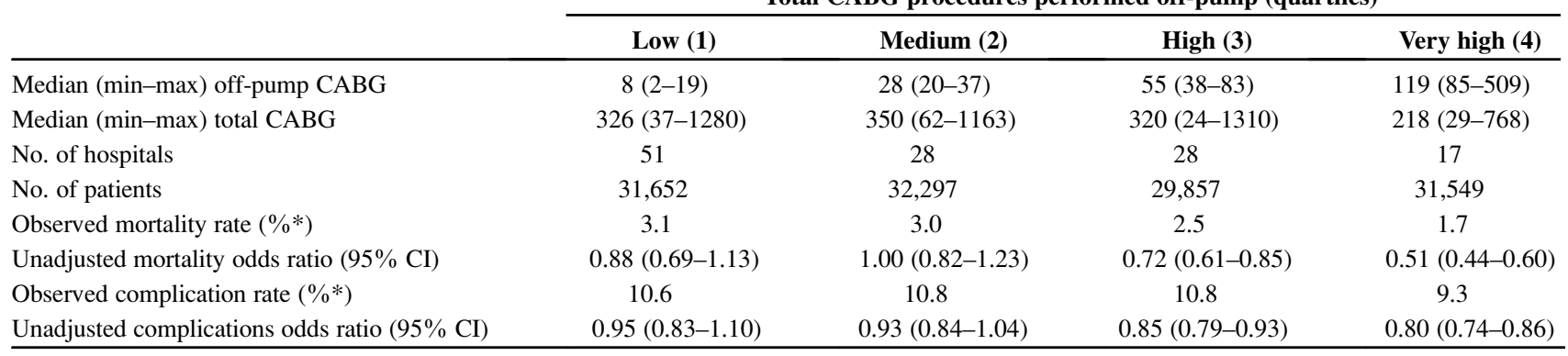

*Cochran-Armitage Trend Test between mortality and volume quartile: $P<.001$ (in-hospital mortality); $P=.001$ (complications).

\begin{tabular}{lcccc} 
& \multicolumn{3}{c}{ Total CABG performed (quartiles) } \\
\cline { 2 - 5 } & Low (1) & Medium (2) & High (3) & Very high (4) \\
\hline Median (min-max) off-pump CABG & $14(2-117)$ & $36(5-245)$ & $49(2-162)$ & $72(24-509)$ \\
Median (min-max) total CABG & $139(24-181)$ & $228(184-206)$ & $366(307-509)$ & $1163(517-1310)$ \\
No. of hospitals & 66 & 31 & 19 & 31,445 \\
No. of patients & 32,063 & 31,332 & 2.5 & 1.4 \\
Observed mortality rate $(\% *)$ & 2.6 & 2.2 & $0.75(0.62-0.91)$ & $0.58(0.45-0.74)$ \\
Unadjusted mortality odds ratio $(95 \% \mathrm{CI})$ & $0.63(0.54-0.74)$ & $0.62(0.52-0.73)$ & 10.5 & 10.7 \\
Observed complication rate $(\% *)$ & 11.1 & 8.5 & $0.85(0.77-0.94)$ & $1.06(0.96-1.17)$ \\
Unadjusted complications odds ratio $(95 \% \mathrm{CI})$ & $0.90(0.83-0.98)$ & $0.69(0.64-0.76)$ &
\end{tabular}

*Cochran-Armitage Trend Test between mortality and volume quartile: $P<.001$ (in-hospital mortality); $P=.48$ (complications).

and that attainment of a certain level of skill in performing off-pump CABG is essential for achieving better outcomes. Nevertheless, even in hospitals performing relatively fewer off-pump procedures, outcomes were no worse than for on-pump CABG.

The clinical and demographic characteristics of patients in our study were comparable with prior retrospective studies $^{28,29}$; however, these studies did not evaluate outcomes relative to surgical volume. Second, the overall mortality and complications were lower in patients who underwent off-pump CABG compared with on-pump CABG-findings also reported previously. ${ }^{3-5}$

Our findings contrast prior studies that failed to demonstrate differences in outcomes in patients undergoing off-pump
CABG in high- and low-volume centers. ${ }^{30-32}$ In a study of 72 hospitals, Brown and colleagues ${ }^{30}$ found no significant mortality benefit but lower postoperative complications for off-pump CABG patients in five high-volume centers $(>100$ off-pump CABG/year). In the Veterans Affairs-based study, Plomondon and coworkers ${ }^{31}$ found no volume-mortality relationship for off-pump CABG. This study included four hospitals that performed 60 or more off-pump CABG operations annually, and none performed more than 100 . These studies were more than likely underpowered to detect any volumerelated differences in outcomes owing to the relatively few hospitals in the high-volume categories.

Glance and coworkers ${ }^{32}$ concluded that the lack of relationship between outcomes and surgeon volumes for 
TABLE 4. Risk-adjusted mortality and postoperative complications for off-pump CABG compared with on-pump CABG by CABG volume quartiles

\begin{tabular}{|c|c|c|}
\hline & In-hospital mortality: OR $(95 \% \mathrm{CI})$ & Postoperative complications: OR $(95 \%$ CI $)$ \\
\hline \multicolumn{3}{|c|}{ Percent CABG performed off-pump (quartiles) } \\
\hline $1(0-6.4 \%)$ & $1.10(0.75-1.63) ; P=.66$ & $0.92(0.72-1.16) ; P=.45$ \\
\hline $2(6.5 \%-11.1 \%)$ & $0.80(0.60-1.06) ; P=.15$ & $0.88(0.75-1.03) ; P=.20$ \\
\hline $3(11.2 \%-22.8 \%)$ & $0.73(0.57-0.94) ; P=.007$ & $0.81(0.71-0.94) ; P=.002$ \\
\hline $4(23.7 \%-89.2 \%)$ & $0.50(0.41-0.61) ; P<.001$ & $0.73(0.66-0.81) ; P<.001$ \\
\hline \multicolumn{3}{|c|}{ Total CABG procedures performed off-pump (quartiles) } \\
\hline $1(2-19)$ & $0.83(0.62-1.11) ; P=.18$ & $0.89(0.76-1.06) ; P=.20$ \\
\hline $2(20-37)$ & $0.77(0.598-1.01) ; P=.09$ & $0.81(0.70-0.94) ; P=.02$ \\
\hline $3(37-83)$ & $0.65(0.51-0.81) ; P<.001$ & $0.80(0.71-0.91) ; P<.001$ \\
\hline $4(85-509)$ & $0.48(0.37-0.63) ; P<.001$ & $0.72(0.62-0.83) ; P<.001$ \\
\hline \multicolumn{3}{|c|}{ Total CABG procedures performed (quartiles) } \\
\hline $1(24-181)$ & $0.67(0.53-0.83) ; P<.001$ & $0.79(0.70-0.90) ; P<.001$ \\
\hline $2(184-306)$ & $0.61(0.47-0.79) ; P<.001$ & $0.77(0.68-0.89) ; P=.001$ \\
\hline $3(307-509)$ & $0.73(0.54-1.00) ; P=.03$ & $0.81(0.69-0.96) ; P=.02$ \\
\hline $4(517-1310)$ & $0.61(0.39-0.96) ; P=.14$ & $0.85(0.68-1.07) ; P=.13$ \\
\hline
\end{tabular}

off-pump CABG suggests that the mechanism for the volume-outcome association for CABG surgery is selective referral, rather than practice makes perfect-an unexpected conclusion given the technical difficulty of off-pump CABG. Although we are unable to directly evaluate the relationship between surgeon experience and outcomes, our findings support the notion that higher volume leads to greater expertise and, therefore, better outcomes. Nevertheless, we cannot rule out selective referral, as patients who are good candidates for off-pump CABG may be referred to facilities with a good reputation for off-pump CABG surgeries.

This study also suggests that results from prior randomized trials may not generalize to all hospitals. One recent multicenter study that demonstrated superior outcomes for off-pump CABG compared with on-pump $\mathrm{CABG}^{3}$ included patients recruited from centers that performed above-average percentages of off-pump CABG procedures: $40 \%$ of overall CABG operations were performed offpump, which is much higher than the national average (ie, $20 \%-25 \%$ of the overall CABG procedures performed off-pump); thus the generalizability of such studies to all hospitals performing off-pump CABG is suspect.

We acknowledge important limitations to our study. First, to our knowledge, no prior studies have examined the reliability of the coding for the use of a pump for CABG surgery in administrative data. Our findings, however, agree with the Society of Thoracic Surgeons' report that roughly 20\% to $25 \%$ of $\mathrm{CABG}$ procedures are performed without the use of the pump. Moreover, if misclassification of the pump use does occur, it would likely be random and unrelated to hospital volume. Nonetheless, these findings should be replicated in clinical databases that are assembled using stricter data collection protocols.

Second, the study was limited to hospitals in California and thus may not be generalizable to the entire country. In
2003, 121 hospitals performed 21,272 isolated CABG operations in California, with an overall operative mortality rate of $2.91 \%$. Nationally, the Society of Thoracic Surgeons reported $2.4 \%$ for the same measure (available at: http:// www.oshpd.ca.gov).

Third, our analysis did not account for physician volume or technical expertise, which is likely to be related to the procedural outcomes. Similarly, our analysis did not account for other organizational factors, such as the preoperative risk assessments and recommendations by other physicians (eg, cardiologists or internists), which may underlie the volume-outcome relationships we observed. Fourth, administrative data do not allow identification of important factors that are related to outcomes as well as the decision to perform $\mathrm{CABG}$ without the pump, such as coronary anatomy, left ventricular systolic function, or the severity of the comorbid conditions. We were also unable to examine longer-term outcomes including graft patency - a critically important outcome for which questions about the efficacy of off-pump CABG remain. Nevertheless, administrative data have been widely used to evaluate outcomes of cardiac surgery, ${ }^{33-36}$ including prior studies of off-pump CABG. ${ }^{37}$ In addition, we attempted to control for patient selection differences using propensity scores, consistent with several prior studies of off-pump CABG. ${ }^{38-42}$

Finally, the intended surgical procedure is not necessarily the procedure indicated in our data, and we were unable to calculate the conversion rate of off-pump CABG to onpump CABG or vice versa. The reported conversion rates of off-pump CABG to on-pump CABG have varied from less than $1 \%{ }^{10}$ in randomized trials to a much higher conversion rate of $5.8 \%$ in retrospective studies using a multicenter cardiac registry database. ${ }^{43}$ In the latter study, an inverse relationship between hospital-level off-pump CABG volume and the conversion of off-pump to on-pump CABG was 
demonstrated. Therefore, in our study, conversion rates from off-pump to on-pump CABG in the highest percent off-pump or off-pump CABG volume quartiles are likely to be low.

Off-pump CABG remains a valuable technique that may benefit patients at high risk for pump-related complications, such as those with diffusely diseased aortas, pulmonary disease, hepatic dysfunction, or bleeding diatheses. In this study, risk-adjusted outcomes were significantly better for patients undergoing off-pump CABG compared with on-pump CABG, and the benefit of off-pump CABG increased steadily as the relative use of off-pump CABG at a hospital increased. Moreover, there was no decrement in outcomes associated with off-pump CABG in hospitals performing relatively few off-pump procedures. Thus, the learning curve for offpump CABG can be safely negotiated across numerous hospitals, raising the hope that as lower volume centers gain experience, risk-adjusted outcomes for CABG patients will improve even further. Broad adoption of off-pump CABG should therefore be encouraged. As facilities adopt this relatively new technology into clinical practice, specialized and focused training will ensure proper implementation. ${ }^{44}$

This study also suggests that results comparing outcomes of on- and off-pump CABG from prior randomized trials involving few centers may not generalize to all hospitals. Finally, this study has important implications for public reporting of CABG surgery outcomes, given that hospitals performing well for on-pump CABG are not necessarily the same as those that perform well for off-pump CABG.

\section{References}

1. Baumgartner WA, Burrows S, del Nido PJ, Gardner TJ, Goldberg S, Gorman RC, et al, for the National Heart, Lung, and Blood Institute Working Group on Future Direction in Cardiac Surgery. Recommendations of the National Heart, Lung, and Blood Institute Working Group on Future Direction in Cardiac Surgery. Circulation. 2005;111:3007-13.

2. Wijeysundera DN, Beattie WS, Djaiani G, Rao V, Borger MA, Karkouti K, et al. Off-pump coronary artery surgery for reducing mortality and morbidity: meta analysis of randomized and observational studies. J Am Coll Cardiol. 2005;46:872-82.

3. Mack MJ, Pfister A, Bachand D, Emery R, Magee MJ, Connolly M, et al. Comparison of coronary bypass surgery with and without cardiopulmonary bypass in patients with multivessel disease. J Thorac Cardiovasc Surg. 2004; 127:167-73.

4. Cleveland JC Jr, Shroyer AL, Chen AY, Peterson E, Grover FL. Off-pump coronary artery bypass grafting decreases risk-adjusted mortality and morbidity. Ann Thorac Surg. 2001;72:1282-9.

5. Al-Ruzzeh S, Ambler G, Asimakopoulos G, Omar RZ, Hasan R, Fabri B, et al. Off-pump coronary artery bypass (OPCAB) surgery reduces risk-stratified morbidity and mortality: a United Kingdom multi-center comparative analysis of early clinical outcome. Circulation. 2003;108(Suppl 1):II1-8.

6. Parolari A, Alamanni F, Polvani G, Agrifoglio M, Chen YB, Kassem S, et al. Meta-analysis of randomized trials comparing off-pump with on-pump coronary artery bypass graft patency. Ann Thorac Surg. 2005;80:2121-5.

7. Angelini GD, Taylor FC, Reeves BC, Ascione R. Early and midterm outcome after off-pump and on-pump surgery in beating heart against Cardioplegic Arrest Studies (BHACAS 1 and 2): a pooled analysis of two randomized controlled trials. Lancet. 2002;359:1194-9.

8. Khan NE, De Souza A, Mister R, Flather M, Clague J, Davies S, et al. A randomized comparison of off-pump and on-pump multivessel coronary-artery bypass surgery. N Engl J Med. 2004;350:21-8.

9. Nathoe HM, van Dijk D, Jansen EW, Suyker WIL, Diephuis JC, van Boven WJ, et al. A comparison of off-pump and on-pump coronary bypass surgery in lowrisk patients. $N$ Engl J Med. 2003;348:394-402.
10. Puskas JD, Williams WH, Mahoney EM, Huber PR, Block PC, Duke PG, et al. Off-pump vs conventional coronary artery bypass grafting: early and 1-year graft patency, cost, and quality-of-life outcomes-a randomized trial. JAMA. 2004; 291:1841-9.

11. Birkmeyer JD, Siewers AE, Finlayson EV, Stukel TA, Lucas FL, Batista I, et al. Hospital volume and surgical mortality in the United States. N Engl J Med. 2002; 346:1128-37.

12. Luft HS, Junt SS, Maerki SC. The volume-outcome relationship: practice makes perfect or selective referral patterns? Health Serv Res. 1987;22: 157-82.

13. Hannan EL, Kilburn H Jr, Bernard HR, O’Donnell JF, Lukacik G, Shields EP. Coronary artery bypass surgery: the relationship between in hospital mortality and surgical volume after controlling for clinical risk factors. Med Care. 1991; 29:1094-107.

14. AHRQ Quality Indicators-guide to patient safety indicators. Version 2.1, revision 3. 2005, Jan 17. AHRQ Pub. 03-R203. Rockville (MD): Agency for Healthcare Research and Quality; 2003.

15. Poulose BK, Griffin MR, Zhu Y, Smalley W, Richards WO, Wright JK, et al. National analysis of adverse patient safety for events in bariatric surgery. Am Surg. 2005;71:406-13.

16. Rosen AK, Rivard P, Zhao S, Loveland S, Tsilimingras D, Christiansen CL, et al. Evaluating the patient safety indicators: how well do they perform on Veterans Health Administration data? Med Care. 2005;43:873-84.

17. Elixhauser A, Steiner C, Harris DR, Coffey RM. Comorbidity measures for use with administrative data. Med Care. 1998;36:8-27.

18. Rubin DB. Estimating causal effects from large data sets using propensity scores. Ann Intern Med. 1997;127:757-63.

19. Hosmer DW Jr, Lemeshow S. Applied logistic regression. New York: John Wiley; 1989.

20. Ash AS, Shwartz M. Evaluating the performance of risk-adjustment methods: dichotomous outcomes. In: Iezzoni LI, ed. Risk adjustment for measuring healthcare outcomes. 2nd ed. Chicago: Health Administration Press; 1997: 427-70.

21. Raudenbush SW, Bryk AS. Hierarchical linear models: applications and data analysis methods. 2nd ed. Thousand Oaks (CA): Sage Publications; 2002.

22. Solomon DH, Losina E, Baron JA, Fossel AH, Guadagnoli E, Lingard EA, et al. Contribution of hospital characteristics to the volume-outcome relationship: dislocation and infection following total hip replacement surgery. Arthritis Rheum. 2002;46:2436-44.

23. Luft HS. The relation between surgical volume and mortality: an exploration of causal factors and alternative models. Med Care. 1980;18:940-59.

24. Hannan EL, O'Donnell JF, Kilburn H Jr, Bernard HR, Yazici A. Investigation of the relationship between volume and mortality for surgical procedures performed in New York state hospitals. JAMA. 1989;262:503-10.

25. Hughes RG, Hunt SS, Luft HS. Effects of surgeon volume and hospital volume on quality of care in hospitals. Med Care. 1987;25:489-503.

26. Peterson ED, Coombs LP, DeLong ER, Hann CK, Ferguson TB. Procedural volume as a marker of quality for CABG surgery. JAMA. 2004;291: 195-201.

27. Rathore SS, Epstein AJ, Volpp KGM, Krumholz HM. Hospital coronary artery bypass graft surgery volume and patient mortality, 1998-2000. Ann Surg. 2004;239:110-7.

28. Williams ML, Muhlbaier LH, Schroder JN, Hata JA, Peterson ED, Smith PK, et al. Risk-adjusted short- and long-term outcomes for on-pump versus offpump coronary artery bypass surgery. Circulation. 2005;112:I366-70.

29. Racz MJ, Hannan EL, Isom OW, Subramanian VA, Jones RH, Gold JP, et al. A comparison of short- and long-term outcomes after off-pump and on-pump coronary artery bypass graft surgery with sternotomy. J Am Coll Cardiol. 2004; 43:557-64.

30. Brown PP, Mack MJ, Simon AW, Battaglia SL, Tarkington LG, Culler SD, et al. Comparing clinical outcomes in high volume and low-volume off-pump coronary bypass operation programs. Ann Thorac Surg. 2001;72:S1009-15.

31. Plomondon ME, Casebeer AW, Schooley LM, Wagner BD, Grunwald GK, McDonald GO, et al. Exploring the volume-outcome relationship for offpump coronary artery bypass graft procedures. Ann Thorac Surg. 2006;81: 547-53.

32. Glance LG, Dick AW, Osler TM, Mukamel DB. The relation between surgeon volume and outcome following off-pump vs. on-pump coronary artery bypass graft surgery. Chest. 2005;128:829-37.

33. Hannan EL, Vaughan-Sarrazin MS, Doran D, Rosenthal GE. Provider profiling and quality improvement efforts in CABG surgery: the effect on short-term mortality among Medicare beneficiaries. Med Care. 2003;41:1164-72. 
34. Showstack JA, Rosenfeld KE, Garnick DW, Luft HS, Schaffarzick RW, Fowles J. Association of volume with outcome of coronary artery bypass graft surgery. Scheduled vs nonscheduled operations. JAMA. 1987;257: 785-9.

35. Konety SH, Vaughan Sarrazin MS, Rosenthal GE. Patient and hospital differences underlying racial variation in outcomes after coronary artery bypass graft surgery. Circulation. 2005; 111:1210-6.

36. Ghali WA, Hall RE, Ash AS, Rosen AK, Moskowitz MA. Evaluation of complication rates after coronary artery bypass surgery using administrative data. Methods Inf Med. 1998;37:192-200.

37. Mack MJ, Brown P, Houser F, Katz M, Kugelmass A, Simon A, et al. Onpump versus off-pump coronary artery bypass surgery in a matched sample of women: a comparison of outcomes. Circulation. 2004;110(11 Suppl. 1): II1-6.

38. Rastan AJ, Eckenstein JI, Hentschel B, Funkat AK, Gummert JF, Doll N, et al. Emergency coronary artery bypass graft surgery for acute coronary syndrome: beating heart versus conventional cardioplegic cardiac arrest strategies. Circulation. 2006;114(1 Suppl):I477-85.
39. Guru V, Glasgow KW, Fremes SE, Austin PC, Teoh K, Tu JV. The real-world outcomes of off-pump coronary artery bypass surgery in a public health care system. Can J Cardiol. 2007;23:281-6.

40. Mizutani S, Matsuura A, Miyahara K, Eda T, Kawamura A, Yoshioka T, et al. Onpump beating-heart coronary artery bypass: a propensity matched analysis. Ann Thorac Surg. 2007;83:1368-73.

41. Mishra M, Malhotra R, Karlekar A, Mishra Y, Trehan N. Propensity case-matched analysis of off-pump versus on-pump coronary artery bypass grafting in patients with atheromatous aorta. Ann Thorac Surg. 2006;82:608-14.

42. Magee MJ, Coombs LP, Peterson ED, Mack MJ. Patient selection and curren practice strategy for off-pump coronary artery bypass surgery. Circulation. 2003;108(Suppl 1):II9-14.

43. Jin R, Hiratzka LF, Grunkemeier GL, Krause A, Page US. Aborted off-pump coronary artery bypass patients have much worse outcomes than on-pump or successful off-pump patients. Circulation. 2005;112(9 Suppl):I332-7.

44. Anderson RP, Carey M, Baram-Clothier E, Mack MJ, Lytle BW. The Society of Thoracic Surgeons/American Association for Thoracic Surgery off-pump training program. Ann Thorac Surg. 2006;81:782-4. 
E-APPENDIX. Risk-adjustment models for in-hospital mortality and postoperative complications

In-hospital mortality

Postoperative complications

Demographic
Age 50-64 y
Age 65-74 y
Age $\geq 75$ y
Age unknown
Female sex
Sex unknown

$1.51(1.29-1.77)$

$2.23(1.94-2.57)$

$3.74(3.21-4.35)$

$1.87(1.58-2.23)$

$1.33(1.22-1.44)$

$1.36(1.18-1.56)$

Race or ethnic group

Other (not African American or white)

Race unknown

Admission year

2002

2003

2004

Admission source

Emergency department

Transferred from other facility

Admission type

Unscheduled

Payer status

Private pay

Medicare

Managed care

Acuity factors

Acute MI- anterolateral

Acute MI-inferoposterior

Acute MI-subendocardial

Acute MI-other

Cardiac catheterization same day as CABG

PCI before CABG during index admission

Multiple-vessel CABG

Previous PCI

Previous CABG

Coexisting conditions

Cardiogenic shock

Arrhythmia

COPD

Congestive heart failure

Cerebrovascular disease

Peripheral vascular disease

Chronic renal failure

Liver disease

Coagulation disorder

Valve disease

Pulmonary/circulation

Weight loss

Alcoholism

Fluid/electrolyte disorder

Model c-statistic
1.28 (1.13-1.44)

$0.84(0.76-0.93)$

$0.75(0.67-0.83)$

$0.78(0.71-0.87)$

$1.36(1.23-1.50)$

$1.21(1.10-1.34)$

$1.09(1.00-1.19)$

$0.68(0.62-0.75)$

-

$1.63(1.44-1.86)$

$1.44(1.25-1.65)$

$1.21(1.10-.33)$

$1.82(1.48-2.23)$

$1.62(1.48-1.78)$

-

-

$1.70(1.41-2.05)$

$4.60(4.01-5.38)$

$1.09(1.00-1.19)$

$1.33(1.23-1.44)$

$1.78(1.65-1.92)$

$1.12(1.00-1.25)$

$1.35(1.23-1.47)$

$2.98(2.69-3.30)$

$3.22(2.54-4.11)$

$1.73(1.48-2.02)$

$1.53(1.38-1.70)$

$1.36(1.14-1.62)$

$1.77(1.35-2.31)$

$1.22(1.08-1.37)$
$1.94(1.68-2.24)$

\section{Odds ratio $(95 \%$ CI $)$}

$1.17(1.09-1.25)$

$1.43(1.33-1.53)$

$1.85(1.71-2.00)$

$1.39(1.27-1.51)$

$1.20(1.14-1.25)$

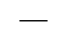

$1.27(1.17-1.37)$

$1.11(1.04-1.19)$

$1.06(1.01-1.12)$

$1.04(1.00-1.09)$

$1.19(1.12-1.25)$

$1.06(1.00-1.12)$

$1.12(1.07-1.18)$

$1.07(1.01-1.13)$

$0.95(0.91-0.99)$

$0.89(0.82-0.97)$

$1.19(1.06-1.35)$

$3.13(2.89-3.40)$

$1.16(1.03-1.31)$

$0.88(0.83-0.93)$

$1.19(1.06-1.35)$

$1.31(1.16-1.48)$

$1.35(1.29-1.42)$

$1.41(1.35-1.48)$

$1.13(1.06-1.21)$

$1.15(1.09-1.21)$

$1.85(1.73-1.99)$

$1.73(1.46-2.05)$

$1.43(1.29-1.58)$

$1.32(1.24-1.41)$

1.17 (1.04-1.32)

$1.92(1.61-2.30)$

$1.18(1.04-1.34)$

-

$M I$, Myocardial infarction; $C A B G$, coronary artery bypass graft surgery; $P C I$, percutaneous coronary intervention; $I A B P$, intra-aortic balloon pump. 